\title{
Do ethnicity and sex of employers affect applicants' job interest? An experimental exploration
}

\author{
Mark Granberg ${ }^{1}$, Niklas Ottosson ${ }^{1,2}$ and Ali Ahmed ${ }^{1 *}$ (i)
}

\begin{abstract}
Starting a business is one way out of unemployment for many people. Having a small pool of job applicants may, however, affect the quality of manpower available to employers. This paper reports the results of an experimental study that examined whether job-seekers discriminate against prospective employers based on those employers' ethnicity and sex. We conducted an experiment with 889 university students, where we presented 10 hypothetical job vacancies in the restaurant sector to the participants. We then asked participants to state their willingness to apply to each job. The ethnicity and sex of the employers were conveyed through employers' names by using typical male and female Arabic- and Swedish-sounding names. Overall, our results provided no evidence of ethnic or sex discrimination by job-seekers against employers.
\end{abstract}

Keywords: Discrimination, Job search, Labor demand, Labor supply, Workers, Employers JEL-classification: J71, J29

\section{Introduction}

Discrimination based on ethnicity or sex is a violation of the Universal Declaration of Human Rights, adopted by the United Nations in 1948, and is prohibited by law in most modern societies. However, research shows that sex and ethnic discrimination remains persistent and prevalent in most, if not all, societies. Ethnic discrimination, for example, is perceived as the greatest barrier to the integration of immigrants across the EU according to an IZA Expert Opinion Survey (Zimmermann et al. 2008). Ethnic discrimination can lead to income disparities (Rubinstein and Brenner 2014), mental health issues (Elias and Paradies 2016), and residential segregation (Dawkins 2004), which incur high societal and individual costs. Similarly, sex discrimination hinders the empowerment of women and economic development generally (Duflo 2012).

\footnotetext{
*Correspondence: ali.ahmed@liu.se

${ }^{1}$ Linköping University, 58183 Linköping, Sweden

Full list of author information is available at the end of the article
}

Research has documented large aggregate disparities among ethnic groups in the labor market and a skewed distribution of earnings between men and women (Blau and Kahn 2017; Blau and Kahn 2000; Altonji and Blank 1999). Labor market disadvantages of ethnic minorities have been found as early as in the initial stages of the hiring process (Baert 2018; Bertrand and Duflo 2017). Explaining differences in earnings between the sexes has proven to be more complicated. Studies have shown inconsistent experimental results, from female applicants not being at a clear disadvantage in the hiring process (Bertrand and Duflo 2017) to being directly discriminated against (Goldin and Rouse 2000). Because of these inconsistent results of hiring discrimination, the wage differential is instead often attributed to the "glass ceiling" (Albrecht et al. 2003), and the fact that women's early careers are more likely to be interrupted by, for example, child rearing (Bertrand et al. 2010; Wood et al. 1993). In the field of economics, employment discrimination has been explained by two sets of theories: theories of taste-based discrimination, 
where employers are hostile to a certain group (Becker 1957), and theories of statistical discrimination, where employers use the perceived average group productivity as a proxy when drawing conclusions about an applicant's productivity (Arrow 1973; Phelps 1972).

Research on labor market discrimination has focused much on employment discrimination by employers against workers. We suggest that discrimination may also occur through the decisions made by applicants during their job search. It is possible that job applicants condition their decisions of whether to apply for a job based on the perceived characteristics of employers, such as ethnicity and sex. This reversed perspective on discrimination, where job applicants discriminate against certain prospective employers, may have notable implications for the success of entrepreneurs who belong to a disadvantaged group. Differences related to ethnicity and sex among self-employed people in the probability of hiring employees as well as in the composition of their employees do exist (Clark et al. 2017; Fairlie and Miranda 2017; Hammarstedt and Miao 2020; Henley 2005). In this study we, therefore, explored whether part of such differences can be attributed to how workers direct their search in the labor market and whether workers make their decisions to apply contingent on the characteristics of potential employers.

To test our conjecture, we performed an experimental study on 889 university students. We asked the students to state their willingness to apply to 10 fictitious and hypothetical job vacancies in the restaurant sector. We tested for sex and ethnic discrimination, signaling the sex and ethnicity of an employer by using typical male and female names and typical Swedish- and Arabic-sounding names. We chose Arabic-sounding names because previous studies have found that people of Middle Eastern and North African origin have been discriminated against in the Swedish labor market (Bursell 2014; Carlsson and Rooth 2007). Additionally, Andersson and Hammarstedt (2011) show that there is a rather high rate of entrepreneurship among immigrants of Middle Eastern background in the Swedish restaurant sector, but that their businesses tend to be less profitable than comparable Swedish-owned businesses.

The main idea is that the hiring process and job matching involves both workers and employers, and that both parties affect the outcome. The aim of this study was, therefore, to test for ethnic and sex discrimination by workers against employers in need of manpower with an online experiment. The question we intended to answer was, do job-seekers discriminate against prospective employers?

\section{Conceptual framework}

Earlier research has focused on labor market discrimination where employers discriminate in their choice of workers (see Bertrand and Duflo 2017 or Baert 2018 for literature reviews). When facing discrimination of this type, some members of the affected groups might abandon hope of employment and instead start their own businesses. But entrepreneurship is highly contextdependent (Schmutzler et al. 2019) and there is little reason to assume that the interactions entrepreneurs engage in should be void of discrimination. For example, ethnic minorities in Sweden face discrimination in the market for small business transfers (Ahmed et al. 2009) and self-employed immigrants in Sweden face discrimination in the credit market when they need financial capital for their businesses (Aldén and Hammarstedt 2016). Another important interaction, which entrepreneurs hoping to grow their businesses must engage in, is the hiring of personnel. If job-seekers can be selective in who they chose to work for, they might be as selective in the jobs that they apply to. Such discrimination could discourage entrepreneurs from disadvantaged groups and be a partial explanation for the observed gap in business creation between men and women (Elam and Terjesen 2010). Also, without this proposed discrimination the entrepreneurial efforts of immigrants (e.g. Pekkala Kerr and Kerr 2020) could be even more apparent.

The main theoretical framework which is customarily applied in economics when analyzing conventional hiring discrimination covers two broad categories of motivations, both of which result in discriminatory outcomes for disadvantaged groups. The first category is taste-based discrimination proposed by Becker (1957). In Becker's formulation, discrimination originates from a taste-parameter in the utility function of the discriminating party, thus in this model the motivation is a pure animus towards people of the group in question. Translating this to our context it is possible that job-seekers are less likely to apply for jobs posted by women or immigrants in order to avoid being subordinate to people for whom they harbor a distaste. Of course, this might work to the employer's advantage insofar as it allows the employer to avoid inadvertently hiring sexist or racist workers.

Followers' attitudes against female leaders have been shown to be a strong predictor of group success (see, e.g., Rice et al. 1980), but a limited applicant pool could still leave female employers less competitive in the market. Even if workers act upon their preferences, they are not necessarily homogeneous across business sectors; workers may self-select into sectors with like-minded workers. If sexist and/or racist workers congregate in certain business sectors, female and/or immigrant entrepreneurs could be dissuaded or unable to pursue opportunities in 
those sectors. The result is entrepreneurial segregation across business sectors akin to the worker segregation that Becker (1957) discussed.

The second category is statistical discrimination (Arrow 1973; Phelps 1972) where the ascription of group characteristics to individuals results in discrimination against those whose abilities do not conform to those of the group. It is important to note that statistical discrimination may be motivated by either false or correct beliefs about the group (Bohren et al. 2019). For example, someone acting on the assumption that women are inferior leaders may or may not be factually correct in that grouplevel assumption but this would still be discriminatory towards a woman who demonstrates excellent leadership abilities. If they instead happen to be incorrect in those assumptions, as Paustian-Underdahl et al. (2014) meta analyses suggests that they would be, they will just be all the more likely to discriminate against an individual. In this way, statistical discrimination against female and/or immigrant business owners may arise even if they are just as competent as their competition; all that is needed is the perception of a difference.

In sum, if discrimination against employers from disadvantaged groups exists, whether statistical or taste-based, the access to a competitive pool of workers might be more limited for some employers, because they are targets of discrimination. This would be especially harmful for immigrant groups, for whom entrepreneurship tends to be an important way of making a living (Borjas 1986; Fairlie and Meyer 1996; Hammarstedt 2001; Yuengert 1995). As entrepreneurship is an avenue for improving one's economic situation, discrimination by job-seekers might play a part in explaining the lower lifetime incomes of these groups by limiting their possibilities for business expansion. Furthermore, this type of discrimination could be especially harmful for small businesses, because of its adverse effect on the early stages of entrepreneurship for both ethnic minorities and women. The perspective on discrimination that we introduce in this paper may also be a partial explanation for increased segregation, as this assortative matching would limit intergroup contact.

\section{Method}

\subsection{Participants}

We conducted a web-based experiment among students at Linköping University to test whether job applicants discriminate against potential employers based on their sex and ethnicity. An e-mail was sent by the university IT department in February 2017, welcoming students to participate in the experiment. A total of 889 students participated in the experiment; 64 percent were women. Statistics on the demographics of the full student body in Sweden were not available to us. However, statistics from the Swedish Council of Higher Education reveal that 53.9 percent of students admitted to the university in 2016 were female. Hence, female participants seem to have been somewhat overrepresented in our sample. Participants' age ranged from 18-67 years $(M=26.39$, $S D=8.16$ ). About 23 percent of the participants had a non-Swedish background (i.e., at least one parent born abroad), 72 percent had some kind of previous work experience (exceeding 12 months), and 40 percent had prior work experience in the restaurant sector.

\subsection{Material}

We presented our participants with fictitious job advertisements and asked them to imagine that they were looking for extra work in the restaurant sector. After reading one of the fictitious job ads, the participants were asked to report the likelihood that they would apply to the position. We randomly assigned Swedish- and Arabic-sounding male and female names to the employers in the job ads. We then looked for differences in participants' stated willingness to apply to a job in relation to the names assigned to the employers.

We constructed 10 fictitious job ads based on real job ads for waitstaff posted at the Swedish Public Employment Service. We chose waitstaff jobs because students often work in this sector to earn extra money. These jobs are also suitable for all students regardless of background or current studies since it does not require prior experience or specific education. The ten fictitious job ads were presented to each participant in a randomized order.

To examine whether the students discriminated against employers with Arabic-sounding names or against women, we needed names that distinctively signaled membership in these groups. For this purpose, we used name data from Statistics Sweden. For Swedish names, 10 female and 10 male names were randomly selected from a list of the top 100 most common first names for each sex. Because Arabic-sounding names are generally not among the 100 most common names in Sweden, we obtained them from a list of all names given to at least 10 newborns in any given year between 1998 and 2015. This list was randomized, and the first 100 Arabic-sounding were identified. Out of the resulting list, 10 female and 10 male names were randomly selected. All 40 selected names are listed in Additional file 1: Material B.

The street names for the employers in the job ads were chosen to correspond to five major streets in the city center of Linköping. The assigned street numbers were higher than those on the actual street, as to avoid presenting an actual address to participants. The restaurants in the ads had credible, impersonal noncontroversial names. 


\subsection{Procedure}

We used the web-based research platform Qualtrics to construct our experiment. This platform offers many of the features that we needed, as well as a way to execute custom JavaScript to construct the randomization functions that were not otherwise possible. Each of the 889 participants was asked to reflect on 10 job ads, where the name of the employer assigned to each ad was chosen randomly. This meant that each participant could respond to ads with names from any group. To ensure that the adverts remained realistic, we used the ads in their original form, replicating the original layout used by the Swedish Public Employment Service, the largest and most used repository for job ads in Sweden and from which we collected the 10 ads used in the experiment. Each job ad was anonymized by replacing company name, contact details and location with the fictitious information.

The experiment started with an introduction welcoming participants, informing them that the study was about the labor market and that the estimated time for completing the study was about $15 \mathrm{~min}$. On a following page, participants were asked to imagine that they were searching for a job as a server in a restaurant. Participants were then given four response choices when asked to state their willingness to apply for each of the jobs: "Would never send an application", "Would probably not send an application", "Would probably send an application", and "Would absolutely send an application". This design allowed no neutral answers because such an option seemed to provide no information for what is an inherently binary question.

The job ads were presented in randomized order. The name of the employer in each job ad was also randomly selected from our list of names. Hence, we had the 10 unique job ads and used JavaScript to randomly select one out of 40 names to assign each ad before presenting it to a participant. This randomization process first selected one of four groups of names (Swedish malesounding, Swedish female-sounding, Arab male-sounding, Arab female-sounding), after which a name was randomly drawn. Although there was no limit to how many times a group was drawn, the names were drawn without replacement. This design meant that we had an independent randomization across groups, but not across names. Thus, it was possible, although unlikely $\left(0.25^{10} \approx 0.0001\right.$ percent chance), that a participant would be shown names from only one group. None of our participants were presented with 10 names of the same sex or ethnicity $\left(0.5^{10} \approx 0.1\right.$ percent chance). The full JavaScript code is available in Additional file 1: Material B.

After evaluating the 10 ads, participants were asked to report their age, sex, and some other background information. Table 1 presents the full description of variables in our experiment. The instructions and questions used in the experiment are available in Additional file 1: Material B. The data that support the findings of this study are available in Zenodo at https://doi.org/10.5281/ zenodo.4028879.

Participants were also asked to select one out of Sweden's 10 largest charitable organizations for the researchers to make a donation. This gave the participants an incentive to complete the study. Information on donation choices and payments is provided in Additional file 1: Material B. A pilot study with 24 participants who were outside the sample population of the final study was conducted before the main study. This allowed us to evaluate response time, test functionality, and clarity and make any necessary adjustments.

\subsection{Limitations}

Although using names to signal ethnicity is common practice in studies of discrimination, a case can be made about the difficulty in discerning whether the signal conveys ethnic background, cultural or religious affiliation, or all simultaneously. We argue that this problem is rather minor in our case, as we are examining whether or not discrimination exists, not why. For the sake of simplicity, we continually refer to discrimination against people with Arabic-sounding names as ethnic discrimination in this paper, although we do not know whether the underlying motive for the discrimination is religious, cultural, or ethnic. Furthermore, it could be argued that the names either do not appear clearly enough to have an impact, or that they appear too clearly in the job ads. We adopted the standard layout used by the Swedish Public Employment Service to reflect the natural conditions in which the signal is displayed. While this presentation of the names is realistic, we believe that it, if anything, understates the strength of the signal. In a natural setting, sending an application would entail composing an e-mail to the employer resulting in a more salient interaction with the name and its associated signals.

One can also question whether the Arabic-sounding female names are easily recognizable as such to the average Swedish participant. At the center of this issue is the fact that there is a greater variety of female than of male names (Lee and Ashcraft 2005). However, most of the female names we chose end with a vowel sound, which is consistent with the way in which Indo-European languages, from which Swedish is derived, tend to construct female names. The exceptions among our selected names are the female names Benin, Sibel and Narin, and the male name Musa. In the lists from which we selected first names; 65.8 percent of all female names ended with a vowel but only 17.4 percent of male names did. This gives 
Table 1 Description of Variables

\begin{tabular}{|c|c|}
\hline Variables & Explanation \\
\hline \multicolumn{2}{|l|}{ Outcome variables } \\
\hline Would apply & 1 if a participant stated that they would definitely or probably apply to a certain job opening, 0 otherwise \\
\hline Strict would apply & 1 if a participant stated that they would definitely apply to a certain job opening, 0 otherwise \\
\hline Strict would not apply & 1 if a participant stated that they would definitely not apply to a certain job opening, 0 otherwise \\
\hline \multicolumn{2}{|l|}{ Explanatory variables } \\
\hline Swedish male employer & 1 if the fictitious employer in a job ad had a Swedish-sounding male name, 0 otherwise (Reference category) \\
\hline Arab male employer & 1 if the fictitious employer in a job ad had an Arabic-sounding male name, 0 otherwise \\
\hline Swedish female employer & 1 if the fictitious employer in a job ad had a Swedish-sounding female name, 0 otherwise \\
\hline Arab female employer & 1 if the fictitious employer in a job ad had an Arabic-sounding female name, 0 otherwise \\
\hline \multicolumn{2}{|l|}{ Control variables } \\
\hline Female & 1 if the participant was female, 0 otherwise \\
\hline Age & {$[18,67]$, a participant's reported age } \\
\hline Non-Swedish background & 1 if the participant had a non-Swedish background, i.e., at least one parent born abroad, 0 otherwise \\
\hline Urban & 1 if the participant originally came from a city with more than 200,000 inhabitants, 0 otherwise \\
\hline Work experience & 1 if the participant has had over one year of work experience of any kind, 0 otherwise \\
\hline Restaurant experience & 1 if the participant has had previous experience of any kind from working in the restaurant industry, 0 otherwise \\
\hline Field of study fixed effects & 1 if the participant studied a particular area of subject (one dummy for each field of study), 0 otherwise \\
\hline Ad fixed effects & 1 if the participant saw a specific ad (one dummy for each of the ten ads), 0 otherwise \\
\hline Sequence fixed effects & 1 if it was the participant's first, second, ..., response. (one dummy for each of the ten possible timings), 0 otherwise \\
\hline
\end{tabular}

Field of study fixed effects: Participants were asked to choose among 18 possible fields of academic study (a categorization adopted from the Swedish Council for Higher Education): computer science; animal care; economics; humanities; health and medical care; journalism, information and communication; law; art, design and media; agriculture, horticulture, forestry and fishery; mathematics; material, construction and manufacturing; science; pedagogy, education, and didactics; religion and theology; social and behavioral science; social work and care; language; and technology and technical industry

some indication of how common it is for Swedish female names to end with a vowel. Thus, we believe that our chosen female names can be assumed to be interpreted as such.

There is an unresolved discussion about the usability of student samples. Exadaktylos et al. (2013) find that, in the context of economic games and social behavior, the differences between the public and a student population are negligible. Belot et al. (2015), however, provide evidence of the contrary, arguing that the use of student samples is more problematic. In our case, the main concern is whether students as a whole are more or less likely to hold discriminatory or prejudiced views. A student sample is unrepresentative in terms of age, which is indicated by the mean age of roughly 26.4 in our data. Further, our sample skews towards women (64.5 percent) and the level of education is higher than for the general population. All three of these factors are associated with lower rates of prejudice as shown in an American context by Charles and Guryan (2008), and in a Swedish context by Johansson (2008). This means that the results of our experiment most likely underestimate the extent of discrimination. We argue that because research has shown that students do tend to be less prejudiced and with the possibly weak stimuli discussed above, that the results of our study are to be viewed as a theoretical lower bound-and therefore underestimate of the extent of discrimination against employers.

\section{Results}

Figure 1 shows the distribution of participants responses over the four possible response choices: "Would never send an application", "Would probably not send an application", "Would probably send an application", and "Would absolutely send an application". The rightward skew of the distribution in Fig. 1 reveals that participants were generally willing to apply to the suggested jobs. It is also clear that there were few apparent differences in participants' responses based on the employers' ethnicity or sex. The distribution of responses is almost identical across both the ethnicity and the sex of the employers.

Nevertheless, we perform regression analyses to examine the robustness of the conspicuous lack of effects in Fig. 1. To simplify the analysis, we dichotomized the outcome variable, classifying "Would never send an application" and "Would probably not send an application" as a no (i.e. 0), and "Would probably send an application" and "Would absolutely send an application" as a yes (i.e. 1). The alternative would be a logit or ordered logit model, presented in Additional file 1: Tables A1, A2 (results are unaffected), or dichotomizing at other cuts of the apply variable. This will be done in Table 4. 


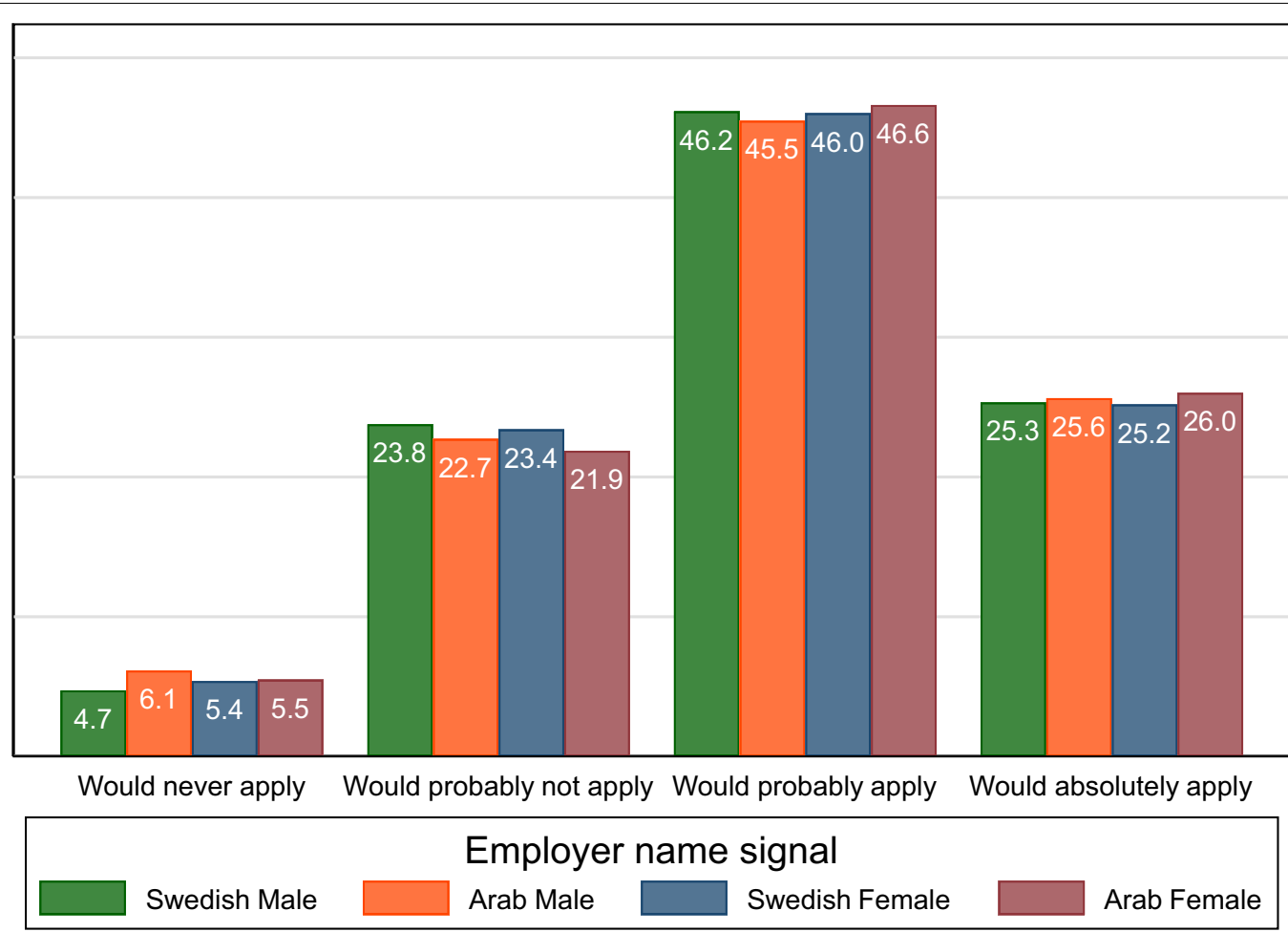

Fig. 1 Percentual Distribution of Responses for Willingness to Apply According to Response Choices and Employers'Ethnicity and Sex. There were 889 participants in the study, each making 10 decisions, which resulted in 8,890 decisions. The full translated answer options were: "Would never send an application", "Would probably not send an application", "Would probably send an application", and "Would absolutely send an application", but they have been shortened for readability in this figure

Table 2 presents linear probability model (LPM) estimates with this binary outcome variable using different sets of controls. The model in column 1 includes only the outcome and treatment and each successive column introduces more covariates. No specification generates significant results for the variables of interest.

Next, we examine the robustness of this apparent null result. Table 3 shows the interaction effects between participants' own identity and their stated willingness to apply i.e. how being female or non-Swedish interacts with ads from employers with those identities. Again, we find no support for any such interaction effects. More explicitly, F-tests of whether the models which included interactions fit the data better than the baseline model $(i v)$ were all statistically insignificant. Model $v(F(2,888)=2.13, p=0.120)$, Model $v i(F(2,888)=0.85$, $p=0.428)$, Model vii $(F(4,888)=1.43, p=0.221)$.

Even though each participant saw completely different ads for each vignette, there is a chance that some social desirability bias affected overall estimates. As each participant saw 10 ads it was possible for him or her to surmise the purpose of the experiment. Therefore, the model in column 1 of Table 4 includes only the first observation for each participant. Point estimates are a bit larger here, but still not statistically significant. The exception is for female Arab employers who seemed to be slightly favored, at the 10 percent level. In column 2 of Table 4 we restricted the sample to those who stated that they could imagine working in the restaurant industry as our experiment presented a more realistic scenario for those participants. However, there are no signs of differential treatment by sex or ethnicity in this subsample.

For the sake of robustness, alternative specifications of the outcome were also checked. Column 3 of Table 4 shows that the null effect persisted when we specified only "Would absolutely send an application" as a yes (i.e. 1). Lastly, column 4 of Table 4 shows estimates when the outcome variable is specified as 1 only if participants selected "Would never send an application", note that this reverses the sign. Here, we see weak evidence of prejudice against Arab men, significant at the 10 percent level. Both of the effects observed in Table 4 are only weakly significant and could well be spurious, so we conclude that our null result holds overall.

Another way to show the lack of effects we have observed is to adopt a Bayesian approach. This approach allows us to show the credible interval for the effect sizes we observe (i.e. the range of values between 
Table 2 Willingness to Apply as a Function of Employers' Ethnicity and Sex

\begin{tabular}{|c|c|c|c|c|c|c|}
\hline & Model $i$ & Model $i^{\mathrm{a}}$ & Model ii & Model $i i^{\mathrm{a}}$ & Model iii & Model $i i^{\mathrm{a}}$ \\
\hline Swedish male & Reference & Reference & Reference & Reference & Reference & Reference \\
\hline \multirow[t]{2}{*}{ Arab male } & -0.004 & 0.003 & -0.003 & 0.004 & -0.002 & 0.005 \\
\hline & $(0.014)$ & $(0.013)$ & $(0.014)$ & $(0.013)$ & $(0.013)$ & $(0.012)$ \\
\hline \multirow[t]{2}{*}{ Swedish female } & -0.003 & -0.004 & -0.004 & -0.004 & 0.003 & 0.003 \\
\hline & $(0.014)$ & $(0.013)$ & $(0.014)$ & $(0.013)$ & $(0.013)$ & $(0.012)$ \\
\hline \multirow[t]{2}{*}{ Arab female } & 0.011 & 0.012 & 0.013 & 0.013 & 0.018 & 0.018 \\
\hline & $(0.014)$ & $(0.013)$ & $(0.014)$ & $(0.013)$ & $(0.013)$ & $(0.012)$ \\
\hline \multirow[t]{2}{*}{ Age } & & & 0.001 & 0.001 & & \\
\hline & & & $(0.001)$ & $(0.001)$ & & \\
\hline \multirow[t]{2}{*}{ Female } & & & $0.051^{* * *}$ & $0.050^{* * *}$ & & \\
\hline & & & $(0.019)$ & $(0.019)$ & & \\
\hline \multirow[t]{2}{*}{ Non-Swedish } & & & -0.004 & -0.004 & & \\
\hline & & & $(0.019)$ & $(0.019)$ & & \\
\hline \multirow[t]{2}{*}{ Urban } & & & 0.014 & 0.014 & & \\
\hline & & & $(0.019)$ & $(0.019)$ & & \\
\hline \multirow[t]{2}{*}{ Restaurant experience } & & & $-0.055^{* * *}$ & $-0.055^{* * *}$ & & \\
\hline & & & $(0.016)$ & $(0.016)$ & & \\
\hline \multirow[t]{2}{*}{ Work experience } & & & -0.030 & -0.030 & & \\
\hline & & & $(0.019)$ & $(0.019)$ & & \\
\hline \multirow[t]{2}{*}{ Constant } & $0.715^{* * *}$ & $0.827^{* * *}$ & $0.673^{* * *}$ & $0.786^{* * *}$ & $0.738^{* * *}$ & $0.863^{* * *}$ \\
\hline & $(0.012)$ & $(0.015)$ & $(0.051)$ & $(0.052)$ & $(0.015)$ & $(0.018)$ \\
\hline Subject controls & & & $\checkmark$ & $\checkmark$ & & \\
\hline Ad FE & & $\checkmark$ & & $\checkmark$ & & $\checkmark$ \\
\hline Participant FE & & & & & $\checkmark$ & $\checkmark$ \\
\hline Sequence FE & & & & & & $\checkmark$ \\
\hline Observations & 8,890 & 8,890 & 8,890 & 8,890 & 8,890 & 8,890 \\
\hline
\end{tabular}

Regressions are linear probability models. Descriptions of all variables are provided in Table 1. Reported standard errors (in parentheses) are corrected for clustering of the observations at the participant level. "FE" is short for fixed effects

${ }^{* * *} p<0.01,{ }^{* *} p<0.05, * 0<0.10$

a Indicates that ad FE have been added to the preceding model

which $95 \%$ of our estimates will be, given the data). To do this we employed a Markov Chain Monte Carlo (MCMC) approach using Metropolis-Hastings sampling with 2500 iterations discarded for burn-in. We drop all but every 10th iteration to avoid issues with autocorrelation in the sampling, so the total number of MCMC-iterations was 102,491, leaving 10,000 in the final MCMC-sample. Given the lack of earlier studies on this research question, we used a rather uninformative $N(0,10)$ prior for the LPM $\beta$-estimates of the effect of treatment on the dichotomized outcome detailed for Table 2. Figure 2 shows the distribution of estimates given our data, and the dashed grey lines indicate the credible interval for each estimate. It is clear that the effects all overlap zero with relatively little spread, there is perhaps some skew towards a positive result for Arab female employers, but all effects are small (the credible interval is below $\pm 4 \%$ in all cases). See Additional file 1:
Figure A1 for other standard descriptive graphs for the MCMC sample which confirm that the sampling did not suffer from any common issues.

We ran some supplementary analyses which can be found in Additional file 1: Material A. Table A1 presents logit estimates and Table A2 presents ordered logit results (all consistent with the results presented here). Table A3 shows that there may have been some minor imbalance of covariates, which indicates that there could have been some self-selection in which students chose to answer the full survey. However, we find this to be an unlikely driver of such a consistent null result. Lastly, Figure A1 shows standard descriptive graphs for the MCMC results.

To summarize, we find no evidence of discrimination against employers based on ethnicity or sex in this online experiment. 
Table 3 Interactions Between Participants' and Employers' Ethnicity and Sex

\begin{tabular}{|c|c|c|c|c|}
\hline & Model iv & Model $v$ & Model vi & Model vii \\
\hline \multirow[t]{2}{*}{ Female employer } & 0.006 & -0.014 & 0.001 & -0.019 \\
\hline & $(0.010)$ & $(0.017)$ & $(0.012)$ & $(0.017)$ \\
\hline \multirow[t]{2}{*}{ Arab employer } & 0.005 & -0.013 & 0.007 & -0.011 \\
\hline & $(0.009)$ & $(0.015)$ & $(0.011)$ & $(0.016)$ \\
\hline \multirow[t]{2}{*}{ Female } & 0.024 & -0.006 & 0.024 & -0.006 \\
\hline & $(0.017)$ & $(0.022)$ & $(0.017)$ & $(0.022)$ \\
\hline \multirow[t]{2}{*}{ Non-Swedish } & 0.001 & 0.001 & -0.007 & -0.006 \\
\hline & $(0.019)$ & $(0.019)$ & $(0.025)$ & $(0.025)$ \\
\hline \multirow[t]{2}{*}{ Female $\times$ Female employer } & & 0.032 & & 0.031 \\
\hline & & $(0.020)$ & & $(0.020)$ \\
\hline \multirow[t]{2}{*}{ Female $\times$ Arab employer } & & 0.028 & & 0.028 \\
\hline & & $(0.019)$ & & $(0.019)$ \\
\hline \multirow{2}{*}{$\begin{array}{l}\text { Non-Swedish } \times \text { Female } \\
\text { employer }\end{array}$} & & & 0.026 & 0.024 \\
\hline & & & $(0.021)$ & $(0.021)$ \\
\hline \multirow{2}{*}{$\begin{array}{l}\text { Non-Swedish } \times \text { Arab } \\
\text { employer }\end{array}$} & & & -0.010 & -0.011 \\
\hline & & & $(0.023)$ & $(0.023)$ \\
\hline \multirow[t]{2}{*}{ Constant } & $0.695^{* * *}$ & $0.714^{* * *}$ & $0.697^{* * *}$ & $0.715^{* * *}$ \\
\hline & $(0.016)$ & $(0.018)$ & $(0.016)$ & $(0.019)$ \\
\hline Observations & 8,890 & 8,890 & 8,890 & 8,890 \\
\hline
\end{tabular}

Regressions are linear probability models. Descriptions of all variables are provided in Table 1. Reported standard errors (in parentheses) are corrected for clustering of the observations at the participant level

*** $p<0.01,{ }^{* *} p<0.05,{ }^{*} p<0.10$

\section{Discussion}

As far as we know, the study reported in this paper is the first to examine discrimination by job applicants against prospective employers. Our results do not provide any evidence of ethnic and sex discrimination against employers by job-seekers. However, the null results are not without reservations either, as our study has some limitations that need to be addressed in future studies on this topic.

First, our sample population most likely represents a lower bound for prejudiced views. Our sample is skewed towards the young, the highly educated, and women, all of which are characteristics associated with less prejudiced views (Charles and Guryan 2008; Johansson 2008). Hence, a sample of participants which is more representative of Sweden's population would be desirable in future studies. Second, because our participants were students, we limited our choice of occupation to the restaurant sector. It is a sector where students without a strong work history can find a job, and where academic major does not matter. However, people may not act on their prejudices if they are just looking for an opportunity to earn extra cash or when they do not intend to commit to a job for an extended period of time. Future research should test the conjecture presented in this paper across various occupations. Finally, we have not accurately replicated the incentives and motivations associated with applying for a job in our experimental setting, the interaction between our sample population and the chosen occupation may not be fully representative of actual conditions. This could result in participants disregarding factors such as sex and ethnicity altogether. Future work on this question would do well to attempt a more natural experiment, as is already common in research on regular hiring discrimination (i.e. correspondence tests), to arrive at a more realistic picture of whether discrimination against employers searching for workers should be a concern.

Table 4 Robustness checks

\begin{tabular}{lllll}
\hline & Model viii & Model $\boldsymbol{i x}$ & Model $\boldsymbol{x}$ & Model $\boldsymbol{x i}$ \\
\hline Outcome variable & Would apply & Would apply & Strict would apply & Strict would not apply \\
Swedish male & Reference & Reference & Reference & Reference \\
Arab male & -0.025 & 0.013 & -0.002 & $0.012^{*}$ \\
& $(0.043)$ & $(0.020)$ & $(0.012)$ & $(0.006)$ \\
Swedish female & -0.031 & 0.005 & 0.003 & 0.001 \\
& $(0.042)$ & $(0.019)$ & $(0.012)$ & $(0.006)$ \\
Arab female & $0.074^{*}$ & 0.017 & 0.007 & 0.003 \\
Constant & $(0.038)$ & $(0.021)$ & $(0.012)$ & $(0.006)$ \\
& $0.737^{* * *}$ & $0.730^{* * *}$ & $0.254^{* * *}$ & $0.051^{* * *}$ \\
Participant FE & $(0.028)$ & $(0.012)$ & $(0.008)$ & $(0.004)$ \\
Observations & & $\checkmark$ & $\checkmark$ & $\mathbf{S}$ \\
\hline
\end{tabular}

For Model viii, the sample was restricted to the first advert each participant saw. Model ix includes only participants who could imagine working in the restaurant industry. For Model $x$ and $x i$, the outcome variable was respecified as described in Table 1 . Regressions are linear probability models. Descriptions of all variables are provided in Table 1. Reported standard errors (in parentheses) are corrected for clustering of the observations at the participant level.

${ }^{* * *} p<0.01,{ }^{* *} p<0.05,{ }^{*} p<0.10$. 

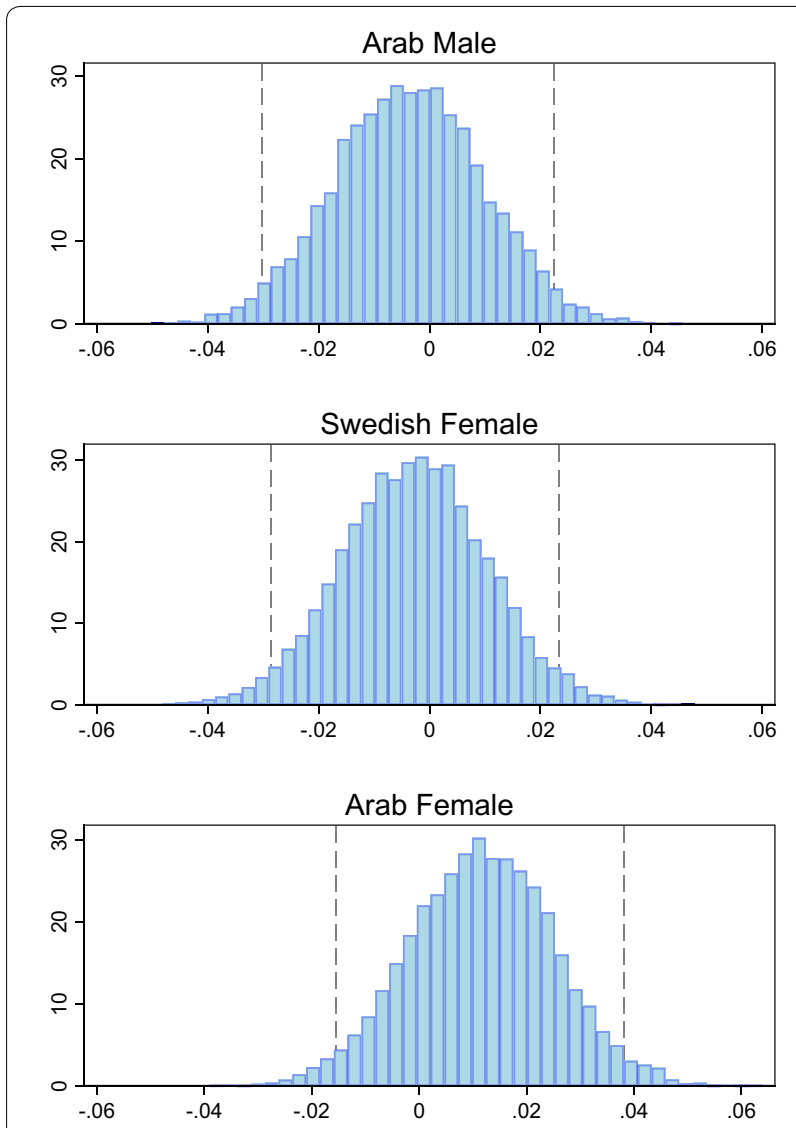

Fig. 2 Histograms of estimated effects sizes for each treatment. These histograms show the distributions of estimates of differences in willingness to apply to different employers (with Swedish Male as the reference category). These distributions were generated using a Markov Chain Monte Carlo approach with Metropolis-Hasting sampling where all but every tenth iteration was discarded to reduce sampling autocorrelation and an uninformative $N(0,10)$ prior was used for the coefficients of interest. Gray dashed lines indicate the 95\% credible interval for each estimate

\section{Supplementary information}

Supplementary information accompanies this paper at https://doi. org/10.1186/s12651-020-00281-x.

Additional file 1. Supplementary analysis and experimental material.

\section{Acknowledgements}

We would like to thank participants at various seminars for their helpful comments and suggestions. We also want to thank David Andersson, Roger Bandick, Joachim Möller, and two anonymous referees for careful comments which greatly improved the paper. The last author was supported by the Swedish Research Council (Grant number: 2018-03487).

\section{Authors' contributions}

The first two authors (MG, NO) contributed equally to the study: they designed the study, collected the data, and wrote the first draft of the paper. All authors (MG, NO, AA) analyzed the data. The last author (AA) supervised the

study and did the final write up of the paper. All authors read and approved the final manuscript.

\section{Funding}

The last author (AA) was supported by the Swedish Research Council (Grant number: 2018-03487).

\section{Availability of data and materials}

The data that support the findings of this study are openly available in Zenodo at https://doi.org/10.5281/zenodo.4028879. The material used in this study is available in Additional file 1: Material B.

\section{Ethics approval and consent to participate}

Not applicable in accordance with the Ethical Review Act in Sweden (Swedish Code of Statutes, 2003:460) as participation in the experiment was voluntary and anonymous (i.e., no personal identifiable information was collected).

\section{Consent for publication}

Not applicable.

\section{Competing interests}

The authors declare that they have no competing interests.

\section{Author details}

${ }^{1}$ Linköping University, 58183 Linköping, Sweden. ${ }^{2}$ The Swedish Unemployment Insurance Inspectorate (IAF), Box 210, 64122 Katrineholm, Sweden.

Received: 23 February 2019 Accepted: 16 October 2020

Published online: 29 October 2020

\section{References}

Ahmed, A.M., Andersson, L., Hammarstedt, M.: Ethnic discrimination in the marketplace of small business transfers. Econ Bull 29(4), 3050-3058 (2009)

Albrecht, J., Björklund, A., Vroman, S.: Is there a glass-ceiling in Sweden. J Labor Econ 21(1), 145-177 (2003)

Aldén, L., Hammarstedt, M.: Discrimination in the credit market? Acess to financial capital among self-employed immigrants. Kyklos 69(1), 3-31 (2016)

Altonji, J.G., Blank, R.M.: Race and gender in the labor market. In: Ashenfelter, O., Card, D. (eds.) Handbook of Labor Economics, pp. 3143-3259. Elsevier, New York (1999)

Andersson, L., Hammarstedt, M.: Invandrares egenföretagande-trender, branscher, storlek och resultat. Ekonomisk Debatt 39(2), 31-39 (2011)

Arrow, K.J.: The theory of discrimination. In: Ashenfelter, O., Rees, A. (eds.) Discriminattion in labor markets, pp. 3-33. Princeton University Press, Princeton (1973)

Baert, S.: Hiring discrimination: an overview of (Almost) all correspondence experiments since 2005. In: Gaddis, S.M. (ed.) Audit studies: behind the scenes with theory, method, and nuance, pp. 63-77. Springer International Publishing, Cham (2018)

Becker, G.S.: The Economics of Discrimination. University of Chicago Press, Chicago (1957)

Belot, M., Duch, R., Miller, L.: A comprehensive comparison of students and non-students in classic experimental games. J. Econ. Behav. Organ. 113(May), 26-33 (2015)

Bertrand, M., Duflo, E.: Field experiments on discrimination. In: Banerjee, A., Duflo, E. (eds.) Handbook of Field Experiments, vol. 1, pp. 309-394. NorthHolland, Amsterdam (2017)

Bertrand, M., Goldin, C., Katz, L.F.: Dynamics of the gender gap for young professionals in the financial and corporate sectors. Econ. J. Appl. Econ. 2(3), 228-255 (2010)

Blau, F.D., Kahn, L.M.: Gender differences in pay. J. Econ. Perspect. 14(4), 75-99 (2000)

Blau, F.D., Kahn, L.M.: The Gender Wage Gap: Extent, Trends, and Explanations. J. Econ. Literat. 55(3), 789-865 (2017)

Bohren, J.A., Imas, A., Rosenberg, M.: The dynamics of discrimination: theory and evidence. Am Econ Rev 109, 3395-3436 (2019) 
Borjas, G.T.: The self-employment experience of immigrants. J Hum Resour 21(4), 487-506 (1986)

Bursell, M.: The multiple burdens of foreign-named men-evidence from a field experiment on gendered ethnic hiring discrimination in Sweden. Eur. Sociol. Rev. 30(3), 399-409 (2014)

Carlsson, M., Rooth, D.-O.: Evidence of ethnic discrimination in the Swedish labor market using experimental data. Lab. Econ. 14(4), 716-729 (2007)

Charles, K.K., Guryan, J.: Prejudice and wages: an empirical assessment of Becker's The Economics of Discrimination. J. Political. Econ. 116(5), 773-809 (2008)

Clark, K., Drinkwater, S., Robinson, C.: Self-employment among migrant groups: new evidence from England and Wales. Small. Bus. Econ. 48(4), 1047-1069 (2017)

Dawkins, C.J.: Recent evidence on the continuing causes of black-white residential segregation. J. Urban Affairs 26(3), 379-400 (2004)

Duflo, E.: Women empowerment and economic development. J. Econ. Lit 50(4), 1051-1079 (2012)

Elam, A., Terjesen, S.: Gendered Institutions and Cross-National Patterns of Business Creation for Men and Women. Eur. J. Dev. Res. 22, 331-348 (2010)

Elias, A., Paradies, Y.: Estimating the mental health costs of racial discrimination. BMC. Pub. Health 16(1), 1-13 (2016)

Exadaktylos, F., Espín, A.M., Brañas-Garza, P.: Experimental subjects are not different. Sci. Rep. 3(1213), 1-6 (2013)

Fairlie, R.W., Meyer, B.D.: Ethnic and racial self-employment differences and possible explanations. J. Hum. Res 31(4), 757-793 (1996)

Fairlie, R.W., Miranda, J.: Taking the leap: The determinants of entrepreneurs hiring their first employee. J. Econ. Manage. Strat. 26(1), 3-34 (2017)

Goldin, C., Rouse, C.: Orchestrating impartiality: the impact of "blind" auditions on female musicians. Am. Econ. Rev. 90(4), 715-741 (2000)

Hammarstedt, M.: Immigrant self-employment in Sweden-its variation and some possible determinants. Entreprenurship. Reg. Deve. 13(2), 147-161 (2001)

Hammarstedt, M., Miao, C.: Self-employed immigrants and their employees: evidence from Swedish employer-employee data. Rev. Econ. Household 18(1), 35-68 (2020)

Henley, A.: Job creation by the self-employed: The roles of entrepreneurial and financial capital. Small. Bus. Econ. 25(2), 175-196 (2005)
Johansson S. (2008):. Unga värderingar-är de annorlunda? In: S. Holmberg, \& L. Weibull, Skilda världar. Trettioåtta kapitel om politik, medier och samhälle. 137-148, Göteborg: SOM-institutet

Lee, J.W., Ashcraft, A.M.: Gender Roles. Nova Science Pub Inc, Hauppauge (2005)

Paustian-Underdahl, S.C., Walker, L.S., Woehr, D.J.: Gender and perceptions of leadership effectiveness : a meta-analysis of contextual moderators. J. Appl. Psychol. 99(6), 1129-1145 (2014)

Pekkala Kerr, S., Kerr, W.: Immigrant entrepreneurship in America: evidence from the survey of business owners 2007 and 2012. Res. Policy 49, 103918 (2020)

Phelps, E.S.: The statistical theory of racism and sexism. Am. Econ. Rev. 62(4), 659-661 (1972)

Rice, R.W., Richer Bender, L., Vitters, A.G.: Leader sex, follower attitudes toward women, and leadership effectiveness: a laboratory experiment. Organizat. Behav. Hum. Perform. 25(1), 46-78 (1980)

Rubinstein, Y., Brenner, D.: Pride and prejudice: using ethnic-sounding names and inter-ethnic marriages to identify labour market discrimination. Rev. Econ. Stud. 81(1), 389-425 (2014)

Schmutzler, J., Andonova, V., Diaz-serrano, L.: How context shapes entrepreneurial self-efficacy as a driver of entrepreneurial intentions: a multilevel approach. Entrepreneurship. Theory. Practice. 45(5), 880-920 (2019)

Wood, R.G., Corcoran, M.E., Courant, P.N.: Pay differences among the highly paid: the male-female earnings gap in lawyers'salaries. J. Labor Econ. 11(3), 417-441 (1993)

Yuengert, A.M.: Testing hypotheses of immigrant self-employment. J. Hum. Res. 30(1), 194-204 (1995)

Zimmermann, K.F., Kahanec, M., Constant, A., DeVoretz, D., Gataullina, L., Zaiceva, A.: Study on the Social and Labour Market Integration of Ethnic Minorities. IZA, Bonn (2008)

\section{Publisher's Note}

Springer Nature remains neutral with regard to jurisdictional claims in published maps and institutional affiliations.

\section{Submit your manuscript to a SpringerOpen ${ }^{\circ}$ journal and benefit from:}

- Convenient online submission

- Rigorous peer review

- Open access: articles freely available online

- High visibility within the field

- Retaining the copyright to your article

Submit your next manuscript at $\boldsymbol{\nabla}$ springeropen.com 